\title{
Analysis of serious games implementation for project management courses
}

\author{
Bonazzi R., Missonier S., Jaccard D., Bienz P., Fritscher B., Fernandes E.
}

\begin{abstract}
Previous researches in pedagogy and project management have already underlined the positive contribution of serious games on project management courses. However, the empirical outcome of their studies has not been translated yet into functional and technical specifications for "serious games" designers. Our study aims at obtaining a set of technical and functional design guidelines for serious game scenario editors to be used in large classes of project management students. We have conceived a framework to assess the influence of different serious games components over student's perceived acquired competency. Such frameworks will allow us to develop a software module for reflective learning, which is meant to extend theory of serious games design.
\end{abstract}

\section{Introduction}

Information system (IS) project management courses are known to be challenging to conceive, since most of the skills required for project managers cannot be achieved ex cathedra. Problems in IS are characterized by incomplete, contradictory and changing requirements, and solutions are often difficult to recognize because of complex interdependencies. This leads to an educational dilemma in teaching such problems because a rich background of knowledge and intuition are needed for effective problem-solving. Hence complexity is added rather than reduced with increased understanding of the problem (Connolly and Stanfield, 2006).

As a consequence of the large number of failed projects a strong challenge to traditional methods of project management based on universal best practices (such as the Project Management Institute) emerges in the academic world and among practitioners (Hodgson and Cicmil, 2007; Sauer and Reich, 2009). Traditional approaches are part of a very instrumental and functionalist vision of promoting project management principles that do not reflect the reality of the projects, which is ambiguous, fragmented, complex, socio-technical built, and with a strong politi- 
cal character. Therefore, project management is a discipline that requires knowledge and reflective practice that allows players to lead the project team in an emergent way. This kind of frameworks requires a high degree of interaction between teacher and students. But face-to-face exchanges are hard to manage when the number of students is greater than forty (Smith and Kampf, 2004).

Game-based learning (also known as serious games) uses simulation to allow students to actively acquire competences required to solve problems. Hence gamebased learning scenarios might be the solution to introduce large classes to IS project management since they are known to have an effect on student's self-efficacy as well as acquisition and retention of declarative and procedural knowledge (Sitzmann, 2011). Yet little interest has been given so far on how to design a scenario editor to support an IS project management course by means of game-based learning. In software engineering courses, game-based simulations are far less used than other types of educational approaches (e.g. industrial partnership or team learning) and they lack to incorporate model-based instruction and reflective learning (Navarro and Van Der Hoek, 2009). We expect a similar trend in IS project management courses. Therefore our research question is:

How to design a game-based learning scenario editor to support an information system project management course for more than forty students?

By adopting a design science methodology this study aims at obtaining a framework to design game-based learning scenario editors to enhances project management competences for students attending the course. Such framework is induced by testing different software components to assess their influences of students' acquired competency. Therefore the creation of a model to assess the software components described in this paper is the initial step of such study. We start here by assessing the gaps in the existing literature and by deriving a conceptual model in the next section. The third section illustrates the methodology we adopt to test our conceptual model and to assess the pedagogical effect of different software tools. The results of a first assessment performed in one of these teaching courses are presented in the fourth section as example. The paper ends by discussing the results obtained and by highlighting the next steps of our study.

\section{Literature review}

This section briefly assesses the state of the art in game-based learning for project management course. We are looking for concrete evidences regarding the link between game-based learning and performance of the IS project management course. Hence we use the guidelines of Okoli and Schabram (2010) for a protocol to assess the existing literature. For sake of simplicity we decide to limit our Google Scholar search to articles published in the period $2005-2010$. Using the 
selected keywords ("project management"; "information systems"; "game-based learning") we obtain 59 results, among which 21 are cited by at least another paper and accessible to us. Since we are interested in articles that have assessed the performance of the serious game analysed, we skim our set of articles to only a few. For those papers we perform forward and backward analysis, i.e. we assess the papers that cite/are cited by them. At the end we obtain two streams of research: ex-ante evaluation and ex-post evaluation. Since we wish to connect these two stream of research we derive three concepts: the student's perceived acquired competency (1), which is the set of measured capabilities that the student acquires in class; the perception of the serious game design (2), which we consider here as the set of features that the game-based learning software possesses to empower the teacher; the student's engagement (3), i.e. the student's will to take part actively to the game-based learning experience.

The first stream of research focuses on the ex ante evaluation of the effect that serious game design has on student's perceived acquired competency. This group of papers claims that while traditional methods are based on an instructivist methodology, game-based learning provides a constructivist learning environment where learners can practice the formulation of requirements specification through requirements elicitation and learning by doing (Hainey and Connolly, 2010). In addition to that game-based learning provides a challenging and complex realworld environment within which to apply their theoretical knowledge to overcome difficulties in dealing with ambiguity and vagueness, while developing selfconfidence and increased motivation (De Freitas et al., 2006).

The second stream of research focuses on the ex post evaluation of the effect that student's engagement having played the serious game has on the student's perceived acquired competency. Researchers collect student's suggestions for game changes (Pfahl et al., 2004; Dantas et al., 2004) and perceived competences needed (Pfahl et al., 2004; Greese von Wangenheim et al., 2009; Zapata, 2010; Mawdesley et al., 2011).

To link these two streams of research we suggest considering the student's engagement as a mediator between serious game design and student's perceived acquired competency. At the end we derive the following set of hypotheses: (H1) the perception of the serious game design influence the student's perceived acquired competency; (H2) the student's engagement influences the student's perceived acquired competency; $(\mathrm{H3})$ the perception of the serious game design influences the student's engagement.

In the next section we illustrate how we intend to design an experiment to test our hypotheses. 


\section{Methodology}

In this section we briefly describe the methodology we use to perform our experiment. Design science seeks for outcomes that can be relevant for practitioners and that have been obtained in a rigorous way. The purpose in this kind of study is usefulness rather than truth. Although design science has been used since many decades, it has been officially accepted in information system since the Management Information System Quarterly article of Hevner et al. (2004). In our study and in this paper we adopt the methodology suggested by Peffers et al. (2008), which proposes a process composed of six steps. Following the first step we clearly identify our problem, using the literature review, as summarized by our research question.

The second step of the methodology identifies the objectives of the solution. In this sense, in the previous section we have identified two gaps in the literature: the first one concerns the link among ex ante and ex post evaluation criteria, whereas the second one regards the use of reflective learning by means of serious games. Thus our study should start by conceiving a framework to assess the correlation among ex ante and ex post evaluation criteria. Then we will move towards the development of an additional module for reflective learning over the student's achieved skills and towards the assessment of its added value.

\section{Design and development}

In the third step of the methodology the design and development of the new component occurs. Yet in the first part of our study described here, the development is minimal since we have decided to reuse an existing serious game. The selected platform to test our assessment framework is a game-based learning scenario editor called Albasim. The main reason underlying the choice of such platform is its large set of existing features and the direct link that the authors have with the development team of the software. This is going to be very useful during the second part of the study, when we will be developing an additional component. Figure 1 illustrates the dashboard used by the game players by means of a web browser. On the top right corner there are the key performance indicators. On the top left corner of the screen the four stages of the game are illustrated: the players start by the project initiation (1), then they move on by planning the project (2) and executing it (3) before closing it (4). The central part of the screen is multifunctional, whereas the right side of the central screen allows the player to manage resources and task, and to read e-mails send by the central system.

For what concerns the reflective learning, the system does not have a dedicated feature, leaving to the teachers the task to arrange students' presentations to share lessons learned, as explained in the following section. 


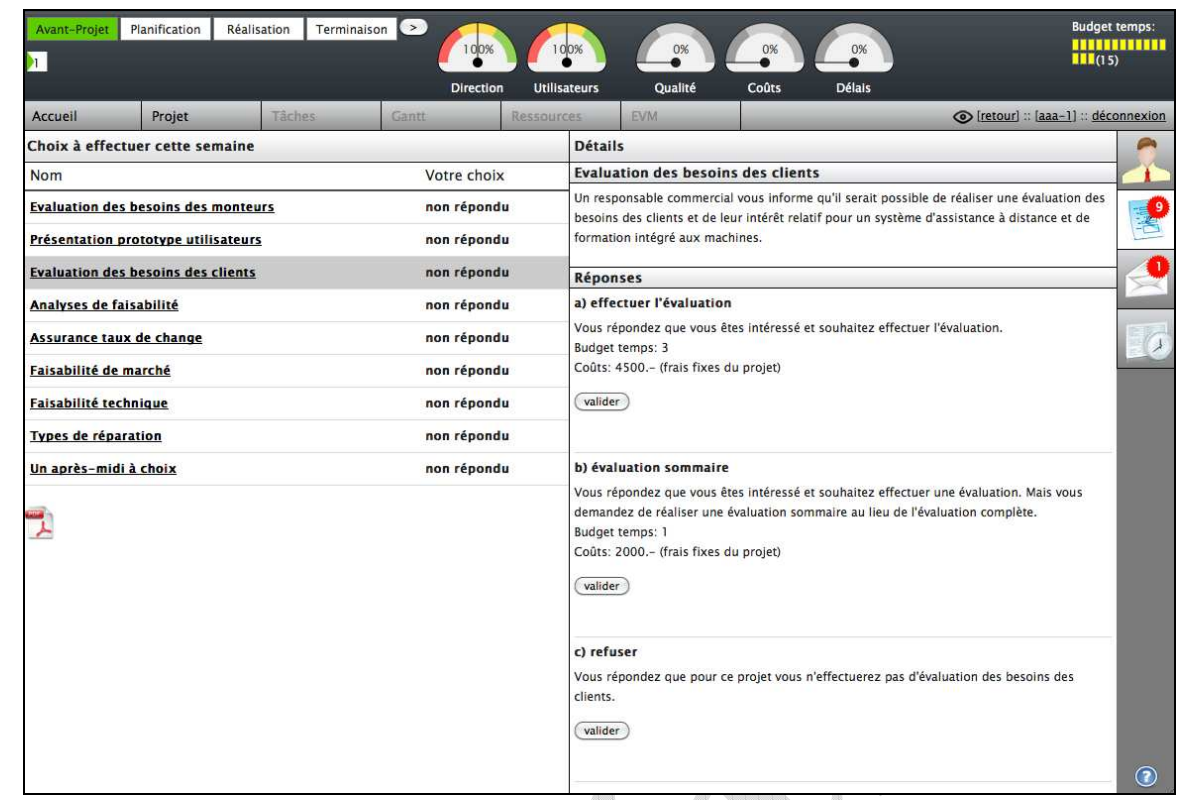

Figure 1: Dashboard of Albasim (Source: www.albasim.com)

\section{The pedagogical scenario implemented}

The fourth step of the methodology of Peffers et al. (2008) requires a demonstration of the artefact. In our case the game requires two four-hour sessions, for a total of eight class hours over two weeks.

Before the first session the students receive the software manual and the business case. At the beginning of the first session students get familiar with the idea of serious game and to the functionalities of the software (e.g. the dashboard). Then the students are asked to gather in group and to collect and process information own by the different fictive players in the game, in order to deliver a project proposal to be validated with the client (i.e. the professor). During the rest of the week the students are supposed to work in group to complete the assignment and send the improved project proposal to the professor, who choses two proposals among them. At the beginning of the second game session the chosen grooups are asked to do a short presentation of their project proposal to the rest of the class. Once two student groups have presented the teachers gives them a constructive feedback and add some remarks about the overall performance of the other groups (best and worst practices). After the presentations the teacher recalls to the class key theoretical concepts regarding project planning. Then the students are asked to work in group to make and to justify their planning decisions, while 
taking into account a set of constraints (time, cost, quality, resources availability and risks). In the rest of the week student groups are ask to finalize the WorkBreakdown Structure, Program Evaluation and Review Technique and Gantt diagrams, together with cost estimations.

\section{Evaluation}

The fifth step of the methodology concerns the evaluation of the artifact. To operationalize our constructs we reuse existing items from the two streams of literature whenver possible and we obtain a set of five-point Likert scale items, which are meant to be collected by questionnaire to be handed once the students have completed the assignments of the second game session. For the student's perceived acquired competency we derive four items inspired by Zapata (2010) and Mawdesley et al. (2011). For the serious game design we implement seven items inspired by Hainey and Connolly (2010) and de Freita and Oliver (2004). For the student's engagement we use seven items inspired by Gresse von Wangenheim et al. (2009) and Dantas et al. (2004). A set of open questions has been collected as well, but their answers will be not presented here for sake of brevity.

\section{Current results}

We have tested the serious game with a sample of bachelor students enrolled in a project management course with a special focus on information systems. We have collected students' perception by means of an electronic survey. We have obtained 74 answers out of the total of 104 students. Although limited in size, we consider this sample as representative for our study and a good starting point to perform statistical analysis using Stata 11 . We started by performing the Cronbach's alpha test over each set of items to measure how well each set of items was representing the concepts. A Cronbach's alpha value of 1.00 would be optimal, whereas a value below 0.70 should be rejected. In our case we obtained the following results: acquired competency $=0.79$; design $=0.80$; engagement $=0.77$.

While testing the causality effect we have performed seemingly unrelated regressions among the three constructs obtained by performing the average of each set of items (i.e tau-equivalent factor loadings). In other words we have asked Stata 11 to tests all the regressions at once.

Figure 2 represents the results that we obtained and it shows that serious game design has also a direct effect over student's acquired competencies, which is statistically significant $(\mathrm{p}<0.01)$. It also appears that the student's engagement has an effect over the student's perceived acquired competency that is statistically significant $(p<0.05)$. Finally the serious game design has an effect over the student's engagement that is statistically significant $(\mathrm{p}<0.01)$. Thus all hypotheses are confirmed. 


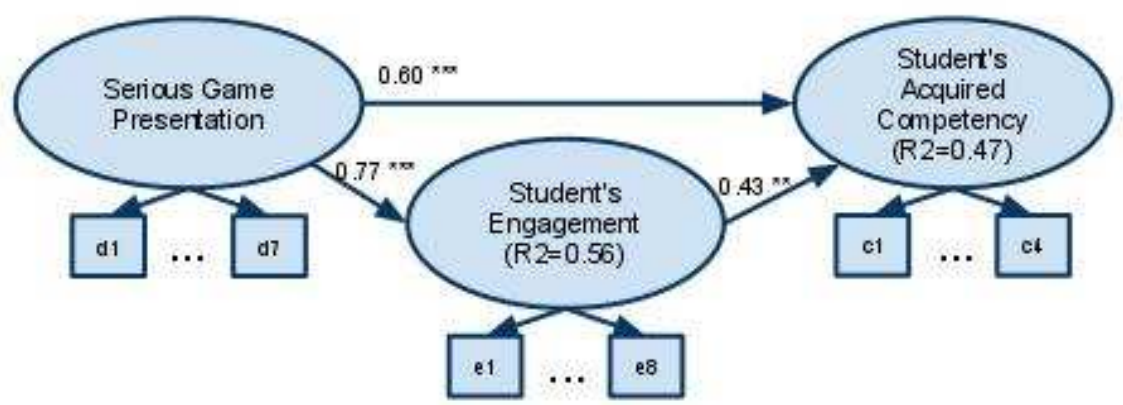

Figure 2: Results of the preliminary test

The direct and indirect effect of serious game design explains almost $50 \%$ of student's perceived acquired competency variance among students $\left(\mathrm{R}^{2}=0.47\right)$. This is to say that none of the two effects should be neglected. In addition to that the student's engagement variability among students is largely explained by serious game design $\left(\mathrm{R}^{2}=0.56\right)$, which leads us to believe this model has a good explanatory power. We have also controlled for the effect of sex and nationality and the results were not statistically relevant.

\section{Conclusions and further works}

We start this section by recalling our research question: How to design a gamebased learning scenario editor to support an information system project management course for more than forty students? In this paper we present our framework to link ex ante and ex post evaluation criteria to assess a game-based learning editor. Now that the framework is in place we can develop the reflective learning module and we can assess its added value by using such module on a subset of the overall students' sample, treating the rest of the class as control group. The results we obtained so far lead us to believe that serious game design has a direct and indirect effect over student's perceived acquired competency, which is mediated by student's engagement. The module we wish to develop has a graphical interface that allows the scenario designer to represent the scenario as a graph. The module is expected to be able to mine the log of student groups' actions and to represent them under the shape of graphs, in order to benchmark the different groups' experience.

In the next iteration we intend to have students groups playing different versions of the same game, whereas the student's acquired competency will be tested with a set of questions in the final exam of the course. These improvements should increase the reliability of our results against endogeneity due to common method variance (Antonakis et al., 2010). 


\section{References}

1. Antonakis, J., Bendahan, S., Jacquart, P., \& Lalive, R. (2010). On making causal claims: A review and recommendations. The Leadership Quarterly, 21(6), 1086-1120.

2. Connolly, T., \& Stanfield, M. (2006). Using Games-Based eLearning Technologies in Overcoming Difficulties in Teaching Information Systems. Journal of Information Technology Education, 5, 459-476.

3. Dantas, A. R., Barros, M. O., \& Werner, C. M. L. (2004). A simulation-based game for project management experiential learning. 2004 International Conference on Software Engineering and Knowledge Engineering (pp. 19-24).

4. De Freitas, S., \& Oliver, M. (2006). How can exploratory learning with games and simulations within the curriculum be most effectively evaluated? Computers \& Education, 46(3), 249264.

5. Gresse von Wangenheim, C., Thiry, M., \& Kochanski, D. (2009a). Empirical evaluation of an educational game on software measurement. Empirical Software Engineering, 14(4), 418452.

6. Hainey, T., \& Connolly, T. M. (2010). Evaluation of a game to teach requirements collection and analysis in software engineering at tertiary education level. Computers \& Education, 56(1), 21-35.

7. Hevner, A. R., March, S. T., Park, J., \& Ram, S. (2004). Design science in information systems research. Management Information Systems Quarterly, 28(1), 75-106.

8. Hodgson, D., \& Cicmil, S. (2007). The Politics of Standards in Modern Management: Making “The Project”a Reality*. Journal of Management Studies, 44(3), 431-450.

9. Mawdesley, M., Long, G., Al-jibouri, S., \& Scott, D. (2011). The enhancement of simulation based learning exercises through formalised reflection, focus groups and group presentation. Computers \& Education, 56(1), 44-52.

10. Navarro, E. O., \& Van Der Hoek, A. (2009). On the Role of Learning Theories in Furthering Software Engineering Education. Ellis, H. J.C. ,Demurjian, S.A. and Naveda J. F., eds. Software Engineering: Effective Teaching and Learning Approaches and Practices (pp. 38-59). IGI Global.

11. Okoli, C., \& Schabram, K. (2010). A Guide to Conducting a Systematic Literature Review of Information Systems Research. Retrieved from http://sprouts.aisnet.org/10-26/

12. Peffers, K., Tuunanen, T., Rothenberger, M. A., \& Chatterjee, S. (2008). A Design Science Research Methodology for Information Systems Research. Journal of Management Information Systems, 24(3), 45-77.

13. Pfahl, D., Laitenberger, O., Ruhe, G., Dorsch, J., \& Krivobokova, T. (2004). Evaluating the learning effectiveness of using simulations in software project management education: results from a twice replicated experiment. Information and Software Technology, 46(2), 127-147.

14. Sauer, C., \& Reich, B. H. (2009). Rethinking IT project management: Evidence of a new mindset and its implications. International Journal of Project Management, 27(2), 182-193.

15. Sitzmann, T. (2011). A Meta-analytic Examination of the Instructional Effectiveness of Computer-based Simulation Games. Personnel Psychology, 64(2), 489-528.

16. Smith, K., \& Kampf, C. (2004). Developing writing assignments and feedback strategies for maximum effectiveness in large classroom environments. Professional Communication Conference, 2004. IPCC 2004. Proceedings. International (pp. 77-82).

17. Zapata, C. M. (2010). A Classroom Game for teaching Management of Software Companies. Dyna, 77(163), 290-299. 